\title{
SATISFAÇÃO DE DISCENTES SOBRE A FORMAÇÃO TÉCNICA E PROFISSIONAL EM INSTITUIÇÕES PÚBLICA E PRIVADA (RIO GRANDE DO SUL, 2013)
}

\author{
E. REDIN ${ }^{*}$, G. B. REIMCHE, G. M. LIXINSKI, J. B. STIVANIN, E. I. SILVA e C. QUADROS \\ Universidade Federal de Santa Maria \\ ezequielredin@gmail.com*
}

Artigo submetido em novembro/2013 e aceito em maio/2015

DOI: 10.15628/holos.2015.1771

\section{RESUMO}

O objetivo do estudo foi avaliar a satisfação dos alunos do último semestre de curso de nível técnico em Administração e Contabilidade de duas instituições - pública e privada - de Santa Maria, Rio Grande do Sul, quanto ao curso escolhido, atendimento, capacitação dos professores, métodos de ensino, atitude, conteúdo e infraestrutura. Os dados foram coletados por meio de um questionário segundo o modelo Kano modificado. Os resultados demonstram que, na instituição privada, os atributos laboratório de impressão e a modernidade dos laboratórios de informática têm maior impacto na satisfação dos alunos. Na instituição pública, o atributo laboratório de impressão e atualização dos professores são considerados os de maior impacto na satisfação. Em termos gerais, o Índice de Satisfação do Cliente Americano ACSI -, considerando os 19 atributos deste estudo, mostra que a instituição privada apresenta um índice de $51,6 \%$, enquanto a pública exibe um índice de $62,1 \%$. Por fim, a pesquisa aponta uma maior satisfação dos alunos na instituição pública, enquanto na instituição privada estabelece-se uma dualidade entre o ensino, recursos humanos e infraestrutura.

PALAVRAS-CHAVE: avaliação do ensino técnico, gestão de qualidade, modelo Kano, gap de melhoria.

\section{SATISFACTION OF STUDENTS ON TECHNICAL ANS PROFESSIONAL TRAINING IN PUBLIC AND PRIVATE INSTITUTIONS (RIO GRANDE DO SUL, 2013)}

\begin{abstract}
The aim of the study was to evaluate the student satisfaction at the last semester of technical college in Administration and Accounting, and compare two institutions - public and private - of Santa Maria, Rio Grande do Sul, and the course chosen, care, training of teachers, teaching methods, attitude, content and infrastructure. Data were collected through a proposed modified Kano questionnaire. The results show that, in the private institution, attributes lab printing and modernity of computer labs have the greatest impact on student
\end{abstract}

satisfaction. In public institution, the attribute lab printing and teacher updating are considered the greatest impact on satisfaction. In general terms, the Index of American Customer Satisfaction - ACSI -, considering the 19 attributes of this study shows that the private institution has an index of $51.6 \%$, while the public shows a higher rate of $62.1 \%$. Finally, the research shows a greater satisfaction of students in public technical institution, while in private institution sets up a duality between education, human resources and infrastructure.

KEYWORDS: evaluation of technical education, quality management, Kano model, gap improvement. 


\section{INTRODUÇÃO}

O panorama brasileiro da educação de nível técnico/profissionalizante apresenta mudanças, sobretudo nos últimos anos, descortinando um cenário que revela a importância da construção de um perfil técnico diferenciado. As mediações dos processos educativos são múltiplas, dadas pelo contexto sociocultural, pelas condições em que se efetiva o espaço de ensino e aprendizagem, pelos aspectos organizacionais, pela dinâmica do funcionamento do projeto políticopedagógico e, de certa forma, pela materialização dos processos de organização, infraestrutura e gestão do ensino profissionalizante.

A procura pelos cursos técnico-profissionalizantes, em diversas áreas do conhecimento, tem sido estimulada pela oferta de vagas no mercado de trabalho. $\mathrm{O}$ mercado aquecido, derivado da crescente demanda na educação profissional, abriu espaço para diferentes instituições ofertarem serviços educacionais, tanto as públicas como também as escolas privadas. De um lado, as instituições públicas, objetivando cumprir uma função social, oferecem esses serviços de forma gratuita, porém, há um acirrado concurso seletivo para aceder a estas vagas. De outro lado, as instituições privadas também ofertam o ensino profissionalizante por meio de processo seletivo, mas com custo financeiro àqueles interessados pelos serviços educacionais.

Este movimento de ampliação da oferta de vagas em cursos técnicos condicionam as escolas a um reordenamento do processo administrativo e operacional, principalmente nas instituições privadas, priorizando a modernização tecnológica e a busca de um quadro docente qualificado, com vistas a atrair candidatos.

A concepção de qualidade na educação é polissêmica, pois se pode referir à organização do trabalho escolar, a infraestrutura, a proposta pedagógica, a formação final, aos processos intermediários, aos recursos tecnológicos, a qualidade dos ingressantes nos cursos, etc. A qualidade é algo dinâmico e processual e, às vezes, atingida de forma rápida e, em outros momentos, de forma estendida no tempo. O quesito qualidade da educação, segundo Dourado, Oliveira e Santos (2007, p. 9), "envolve múltiplas dimensões, não podendo ser apreendido apenas por um reconhecimento de variedade e das quantidades mínimas de insumos considerados indispensáveis ao desenvolvimento do processo ensino-aprendizagem e muito menos sem tais insumos". Neste sentido, a qualidade na educação compreende, na concepção de Dourado, Oliveira e Santos (2007, p. 9), "a relação entre os recursos materiais e humanos, bem como a partir da relação que ocorre na escola e na sala de aula".

Tais fatores denotam uma percepção da realidade, produto da interação entre docentes, discentes e instituição que competem no escopo das interações sociais, culturais, ambientais, econômicas. Ao propor este estudo vislumbramos que a pluralidade, a complexidade e as particularidades de cada instituição são moldadas pelas características específicas de determinadas condutas e características culturais previamente estabelecidas, portanto, qualquer ação estratégica deve levar em consideração estes pressupostos, para então, propor possíveis soluções na construção de projetos para alavancar o nível de qualidade da educação.

Para apreender sobre a satisfação da qualidade de ensino técnico dos alunos, no âmbito escolar, comparou-se duas instituições de ensino, uma pública e uma privada. Assim sendo, o estudo objetiva avaliar a satisfação dos alunos do último semestre de nível técnico em Adminis- 
tração e Contabilidade, comparando duas instituições - pública e privada - de Santa Maria, Rio Grande do Sul, quanto ao curso escolhido, atendimento, capacitação dos professores, métodos de ensino, atitude, conteúdo e infraestrutura.

Estruturalmente este artigo é composto, além desta introdução, de uma breve revisão bibliográfica, seguido da apresentação do método e do lócus de pesquisa educacional e a sua realidade diante da dinâmica do tempo/espaço e, posteriormente, os resultados e discussões. Por fim, são tecidas as considerações finais deste estudo.

\section{REVISÃO BIBLIOGRÁFICA}

Estudos recentes no campo das Ciências Sociais Aplicadas têm se encarregado de elaborar análises, interpretações e teorias em torno da satisfação dos serviços ofertados aos clientes. Dessa analogia, pode-se inferir que uma organização escolar entende seus alunos como clientes. Nesse sentido, é importante a definição de serviço e satisfação.

\subsection{Serviço e Satisfação}

Zeithaml e Bitner (2003, p. 29) afirmam que o "serviço ao cliente é o serviço prestado para dar apoio ao grupo de produtos principais de uma empresa". Kotler (1998) ressalta que a satisfação pós-compra do cliente depende do desempenho da oferta em relação às expectativas desse.

Pensando nas escolas como organizações que ofertam serviços educacionais, parte-se da premissa de que a satisfação dos alunos em relação aos serviços prestados é uma questão fundamental para o sucesso das organizações. De acordo com Kotler "satisfação é o sentimento de prazer ou de desapontamento resultante da comparação do desempenho esperado pelo produto (ou resultado) em relação às expectativas da pessoa" (Kotler, 1998, p. 53).

Conforme Kotler, a satisfação é importante às empresas, pois é por meio dela que se pode atrair novos clientes, neste caso, alunos. Sem divergir deste autor, Souza (2011) afirma que a satisfação "é uma das chaves para o sucesso das empresas, pelo que muitas organizações procuram compreender e avaliar os seus atributos mais importantes" (p. 4). É por meio dela que a empresa poderá fazer uma análise da importância do seu produto, comparando-o com o seu desempenho. Esta prática "permite à organização ter uma visão sobre quais atributos de seu produto ou serviço devem ser melhorados para proporcionar satisfação aos clientes" (Walter, Tontini e Domingues, 2006, p. 26).

Aragão (2012) ressalta que as instituições de ensino são mais complexas do que uma empresa com função meramente lucrativa, sendo a sua função social a questão valorativa mais importante para este tipo de organização, o que exigiria delas uma articulação de sujeito - diretores, professores, alunos, pais e sociedade em geral - para a educação da sociedade, dificultando as noções de produto/serviço, produtor, cliente e produtividade.

É neste cenário que as instituições escolares devem verificar qual a melhor estratégia a ser adotada, sendo "crucial a aquisição de habilidades gerenciais por parte dos profissionais da educação, o que se faz com um forte e estruturado programa de capacitação, on the job e just in time" (Xavier, 2006, p. 17), independentemente de ser pública ou privada (Goldbarg, 1998). 
Buscar a qualidade em ensino e aprendizagem implica desenvolver um processo crítico da aprendizagem, e isso pode acontecer com a permanência do aluno no sistema, evitando a reprovação e a evasão. A busca da qualidade também pode acontecer com a melhoria contínua dos processos pedagógicos, técnicos e administrativos da escola, com a procura permanente da excelência.

\subsection{Satisfação na instituição escolar}

Numa instituição escolar é relevante avaliar o grau de satisfação dos seus alunos, de forma com que a organização verifique e acompanhe como funcionam suas estratégias e se os seus objetivos estão sendo alcançados. É imprescindível que instituições de ensino não percam o foco na qualidade dos seus processos e estruturas ofertadas, devendo ficar atentas à satisfação e aproveitamento dos alunos (Nóvoa, 1999). Marcheti et al. (2005) apontam que não importa a modalidade ou turno das aulas, o objetivo do ensino deve ser a aprendizagem e formação do estudante, ou seja, o desenvolvimento pleno das suas competências cognitivas, sociais e afetivas.

O desenvolvimento das estratégias de qualidade pode gerar a satisfação e a motivação, que são aspectos determinantes nas escolhas e estratégias adotadas pelas pessoas ao longo da vida. Estas passam a influenciar significativamente seu envolvimento, comprometimento, dedicação e realização nas experiências cotidianas. Samulski (1995) destaca que a motivação em geral é caracterizada como um processo ativo, intencional e dirigido a uma meta, ou seja, apresenta uma determinante energética - nível de ativação - e uma determinante de direção do comportamento - intenções, interesses, motivos e metas. Souza e Reinert (2010) citam alguns fatores que influenciam positivamente a satisfação dos estudantes: presença de amigos no grupo, identificação com o curso, interação e postura do professor e a percepção do ensino como algo proveitoso.

Ainda pode-se apontar que, numa instituição de ensino, a satisfação dos usuários envolve dois aspectos: de um lado, a percepção da sociedade que recebe o sujeito que concluiu o curso e que, na dependência do seu desempenho técnico e humano propaga uma imagem positiva da instituição de ensino, desencadeando novas demandas. De outro lado, os alunos podem ter uma percepção de momento ou de futuro dos serviços que recebem, com um nível de satisfação quanto a diversos atributos internos da instituição de ensino, como coordenação, professores, exigência dos estudos, atendimento da secretaria, infraestrutura e biblioteca. Essa satisfação também influencia na demanda, pois os alunos comunicam-se com colegas e a sociedade em geral (Walter et. al., 2006). Assim, os alunos que se sentem satisfeitos influenciarão positivamente a percepção da sociedade e dos futuros discentes a seu respeito, aumentando a demanda daquela instituição.

Há, portanto, um envolvimento e uma relação entre inúmeros componentes: professores, alunos, objetivos e conteúdo de ensino, atividades de aprendizagem e de avaliação, ambiente virtual e material bibliográfico. Esses componentes são suscetíveis a inúmeras variações, daí advém que a avaliação do curso deve ser contínua e capaz de captar os erros e acertos, as dificuldades e facilidades para cada grupo particular de professores, alunos e conteúdos (Carlini; Ramos, 2009).

Existem, ainda, alguns fatores que poderão influenciar negativamente o grau de satisfação dos alunos, como a má organização, o despreparo e o pouco compromisso demonstrado pelos professores para com as turmas e a falta de disponibilidade do corpo docente. Conforme Mo- 
ran, Masetto e Behrens (2013), um bom curso depende de se ter administradores, diretores e coordenadores mais abertos, que entendam todas as dimensões que estão envolvidas no processo pedagógico, além das empresariais ligadas ao lucro; que apoiem os professores inovadores, que equilibrem o gerenciamento empresarial, tecnológico e o humano, contribuindo para que haja um ambiente de maior inovação, intercâmbio e comunicação.

O estado da arte sobre a qualidade na educação nos leva a avaliações que sejam capazes de medir a satisfação dos estudantes com os seus cursos. Entre os métodos possíveis para tais avaliações encontra-se aquele desenvolvido por Kano (1984). Para que a instituição escolar não possua um grau de satisfação negativo, deverá trabalhar os atributos do seu produto/serviço para melhorar o seu desempenho. Kano et al. (1984) e Berger et al. (1993) sugerem que os atributos podem ser identificados perguntando aos consumidores sobre sua reação ou satisfação. É isso que demonstramos na sequência.

\section{MATERIAIS E MÉTODO}

O estudo foi realizado por meio de uma amostra de 66 alunos do último semestre de cursos de técnico em Administração e Contabilidade de duas instituições de ensino, sendo uma privada e a outra pública, ambas localizadas em Santa Maria, Rio Grande do Sul, em 2013. A população amostral foi composta pelos alunos presentes nas salas de aula no dia da avaliação, sendo 33 (50\%) aplicados no colégio técnico público e 33 (50\%) no privado.

Para a elaboração desta pesquisa, utilizou-se o método quantitativo, usando como instrumento de coleta de dados um questionário pelo qual se visou obter, da melhor forma, a satisfação dos alunos com relação a diversos atributos, relacionando o ensino-aprendizagem e a estrutura dos centros de ensino. Os atributos pesquisados foram identificados por meio de pesquisa bibliográfica pela qual se buscou identificar os atributos mais importantes em uma instituição de ensino. A investigação baseou-se na análise da satisfação de 19 atributos, os quais foram agrupados em seis categorias primárias: atendimento (3), capacitação dos professores (3), métodos de ensino (4), atitude (2), conteúdo (3) e infraestrutura (4).

O instrumento de pesquisa foi construído com base no questionário proposto por Tontini e Sant'ana (2007) e foi composto por quatro seções, além de alguns dados demográficos iniciais. Na primeira seção o aluno respondente foi arguido quanto à sua satisfação diante de situações como imaginário de suficiência e insuficiência e quanto ao desempenho atual de cada atributo, também chamadas de perguntas funcionais e disfuncionais, baseando-se no modelo de Kano (1984) para avaliar o impacto do desempenho do atributo na satisfação e insatisfação dos discentes.

A escala empregada para as respostas e para classificar o nível de satisfação do aluno foi proposta por Tontini e Silveira (2005), e variou de totalmente satisfeito (+4) a totalmente insatisfeito (-4) para cada resposta. Para evitar a simetria nas respostas, as questões positivas e negativas foram dispostas em ordem randômica na primeira seção do questionário. Na próxima seção o questionário pedia aos respondentes uma mensuração quanto à sua satisfação com o desempenho atual dos atributos pesquisados, seguindo a mesma escala citada anteriormente. Na terceira sessão o aluno era questionado quanto à importância de cada atributo usando uma escala que 
variou de 1 a 9, onde 1 correspondia a sem importância e 9 a extremamente importante. Na quarta seção foi avaliada a satisfação geral com a instituição.

Com os dados da primeira seção, prosseguiu-se para a etapa de identificação dos atributos usando o modelo Kano modificado (Tontini, 2003), sendo que este permite a determinação do grau de satisfação ou insatisfação que a existência ou inexistência de certo atributo podem trazer aos alunos. Desta forma, foram calculados os coeficientes de satisfação (Cs) e insatisfação (Ci) dos atributos (Tontini, 2003).

Para classificação dos atributos, os coeficientes calculados - Cs e Ci - foram plotados em um gráfico com quatro quadrantes. A localização dos atributos nos quadrantes informa a classificação do atributo segundo o modelo Kano. Os atributos podem ser classificados em atrativos, pois trazem maior satisfação, quando têm desempenho superior, que insatisfação, quando têm desempenho inferior. Atributos unidimensionais, quando trazem tanto satisfação, quando apresentam desempenho superior, como insatisfação, quando apresentam desempenho inferior. Os atributos obrigatórios, que trazem alta insatisfação quando insuficientes e que, porém, não trazem grande satisfação quando suficientes. Por último, os neutros.

Segundo Tontini e Sant'Ana (2008), o modelo Kano é limitado por não levar em conta o nível de desempenho atual. Para levar em conta o desempenho atual dos atributos das instituições estudadas empregou-se também o método dos Gaps de satisfação e insatisfação, proposto por Tontini e Silveira (2005). Este método leva em consideração as perguntas do modelo Kano, bem como a satisfação atual por meio do cálculo dos gaps, desta forma tem-se uma melhor visualização do desempenho atual dos atributos, visando obter os atributos prioritários para melhora nas instituições estudadas. Para o cálculo dos gaps, foi usado o modelo melhorado proposto por Tontini e Sant'Ana (2008), eliminando distorções causadas pelas avaliações negativas dos alunos, tornando o gráfico mais preciso. Usando os resultados de desempenho e importância dada aos atributos foi feita a análise de importância versus desempenho para uma análise final dos resultados num todo, podendo cruzar estas informações com as demais e obter um diagnóstico mais preciso.

Para obter uma visão global do nível de satisfação dos alunos quanto as instituições estudadas, calculou-se o índice de satisfação global, que foi baseado no modelo do Índice de Satisfação do Cliente Americano - ACSI -, proposto por Fornell et al. (1996).

\section{RESULTADOS E DISCUSSÃO}

\subsection{Dados demográficos}

Dentre os achados da pesquisa, com relação às questões demográficas gerais, os resultados dos dois cursos foram bastante semelhantes, sendo que, na média, o número de estudantes do gênero feminino foi expressivamente maior - 70\% -, contra $30 \%$ dos homens. Os dados também mostraram que mais da metade - $56 \%$ - dos respondentes possuem idade média entre 17 e 23 anos, e $26 \%$ entre 24 e 29 anos. A maioria - $82 \%$ - são pessoas solteiras e que possuem trabaIho fixo $-65 \%$.

\subsection{Análise segundo o modelo Kano}


Quanto aos tributos de satisfação, a análise dos resultados, seguindo o modelo Kano, encontra-se representado no gráfico de dispersão do coeficiente de satisfação (figuras $1 \mathrm{~A}$ e B). Observa-se que a linha divisória para criação dos quadrantes foi estabelecida em $+0,5$ para satisfação e -0,5 para insatisfação.
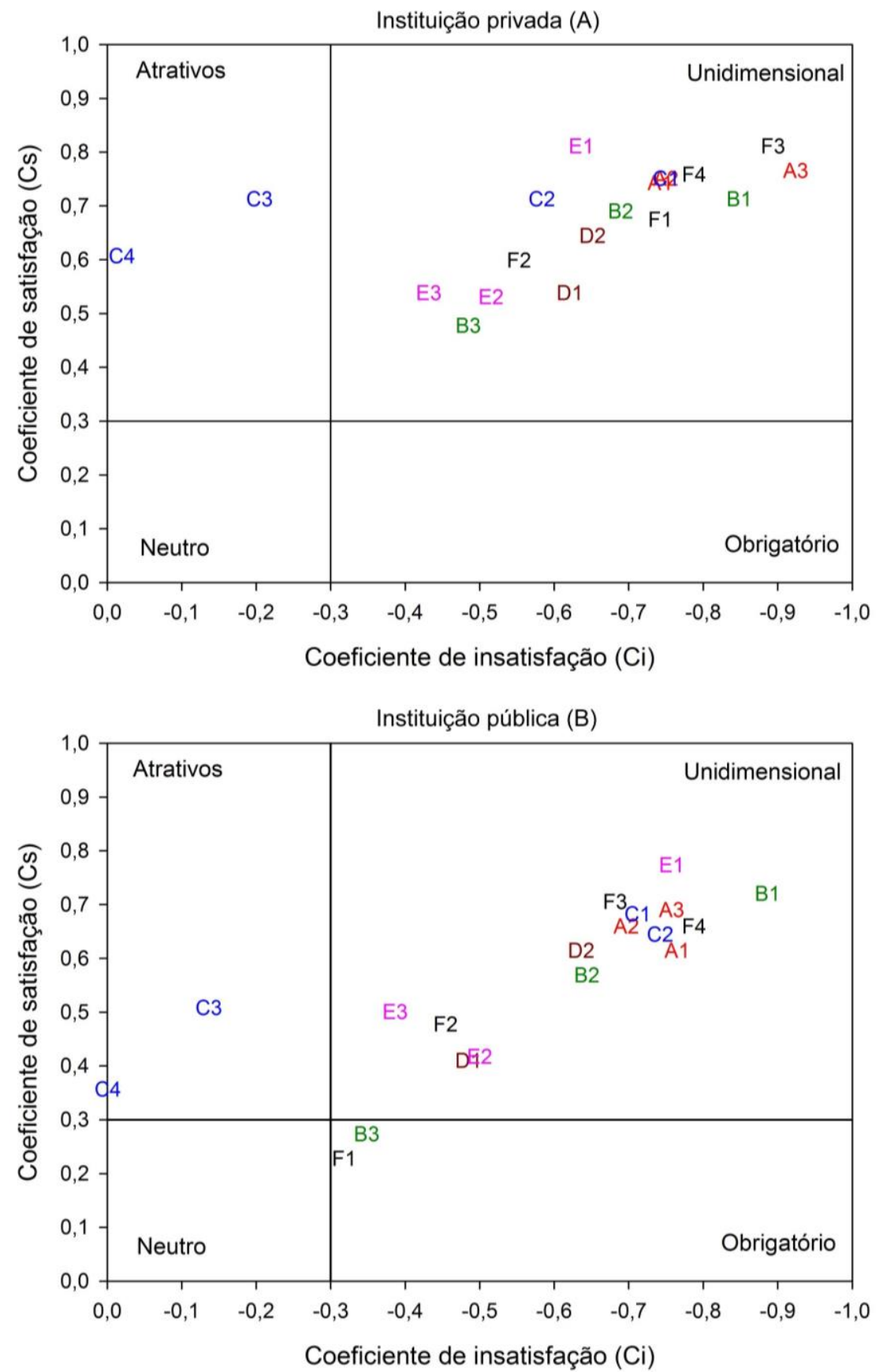
A1 Atendimento da secretaria
A2 Acesso à coordenação do curso
A3 Laboratório de impressão
B1 Atualização dos professores
B2 Titulação dos professores
B3 Exigência por parte dos professores
C1 Experiência prática dos professores
C2 Diversidade de métodos de ensino
C3 Rel. entre teoria e prática
C4 Rel. ensino presencial e extraclasse

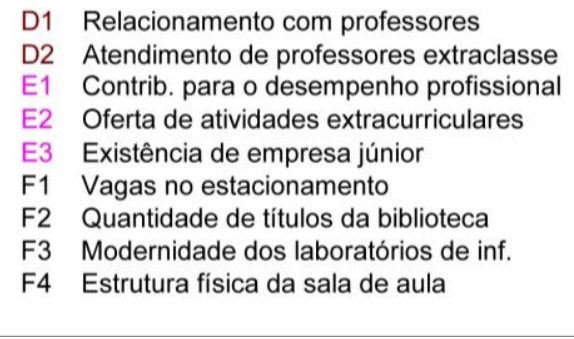

Figura 1: Gráfico de dispersão do coeficiente de satisfação segundo o modelo Kano dos alunos da instituição privada (A) e pública (B). 
Analisando-se a figura 1A, que mostra a classificação dos atributos avaliados pelos alunos da instituição privada, verifica-se que os atributos relação entre aulas teóricas e práticas (C3) e relação ensino presencial e extraclasse (C4) estão estabelecidos como atrativos. Atributos atrativos apresentam maior impacto na satisfação, se melhorados, do que insatisfação, se piorados (Tontini; Sant'ana, 2007). Esse atributo pode ser explorado pela instituição.

Observa-se, também, a existência de um cluster de atributos que engloba a grande maioria dos atributos e inclui todos da categoria atendimento (A), capacitação dos professores (B), atitude (D), conteúdo (E) e infraestrutura (F) entre outros, que apresentam características de atributos unidimensionais, cujo impacto na satisfação é proporcional ao nível de desempenho, ou seja, quanto maior o atendimento, maior será a satisfação dos alunos, ou vice-versa.

Na figura 1B, referente a instituição pública, os atributos nível de exigência por parte dos professores (B3) e vagas no estacionamento (F1), caracterizam-se como obrigatórios, isto significa que são atributos cuja melhora ou presença não traz satisfação e sua ausência não traz insatisfação ao aluno, porém cabe ressaltar que estão bem próximos ao quadrante neutro, podendo variar dependendo da dinâmica da instituição.

São atributos caracterizados como atrativos a relação entre aulas teóricas e práticas (C3), a existência de empresa júnior e a relação ensino presencial e extraclasse (C4), porém, existência de empresa júnior (E3) e a oferta de títulos na biblioteca (F2), devido sua proximidade com o quadrante, poderá oscilar também para o atributo atrativo. Esses atributos atrativos são chaves para satisfação do aluno.

Como unidimensionais são todos os atributos categorizados dentro de atendimento (A) e atitude (D) entre outros, muito semelhante a outra instituição.

Nessa instituição o atributo exigência por parte dos professores (B3) e vagas no estacionamento (F1), mesmo estando muito próximos da zona de neutralidade, ainda foram caracterizados como obrigatórios, sendo que, se estes não apresentarem nível de desempenho suficiente os alunos ficarão totalmente insatisfeitos. Entretanto, caso já estiver suficiente, ele não trará mais satisfação, ou seja, o atributo aqui é de certa maneira visto pelos alunos como um prérequisito.

\subsection{Análise dos gaps de melhoria}

Para as ações direcionais de esforço de melhoria é primordial que seja avaliada a situação atual do desempenho e procurar determinar qual a satisfação adicional que poderá ser conseguida pela melhoria de um atributo. Por meio da comparação dos valores de Kano(+) (desempenho superior) e Kano(-) (desempenho inferior) com a satisfação atual, calculou-se os gaps de satisfação com aumento ou diminuição no desempenho de cada atributo.

A figura 2A e B mostra os gaps de satisfação para os atributos estudados. Para cada atributo existem duas barras, a gap positivo mostra o incremento ou ganho na satisfação esperado com a melhora ou oferta do atributo, e a outra, gap negativo, mostra decréscimo de satisfação esperado pela piora ou ausência do atributo. As linhas divisórias de neutralidade foram estabelecidas considerando a média para cada Kano. Desta forma, atributos que apresentam incremento de satisfação maior que esta média - positiva - são considerados relevantes para a melhoria ou sua oferta aos alunos da instituição. Já os que apresentam insatisfação média inferior à média - 
negativa - com sua ausência são considerados significativos, pois poderão gerar insatisfação geral.

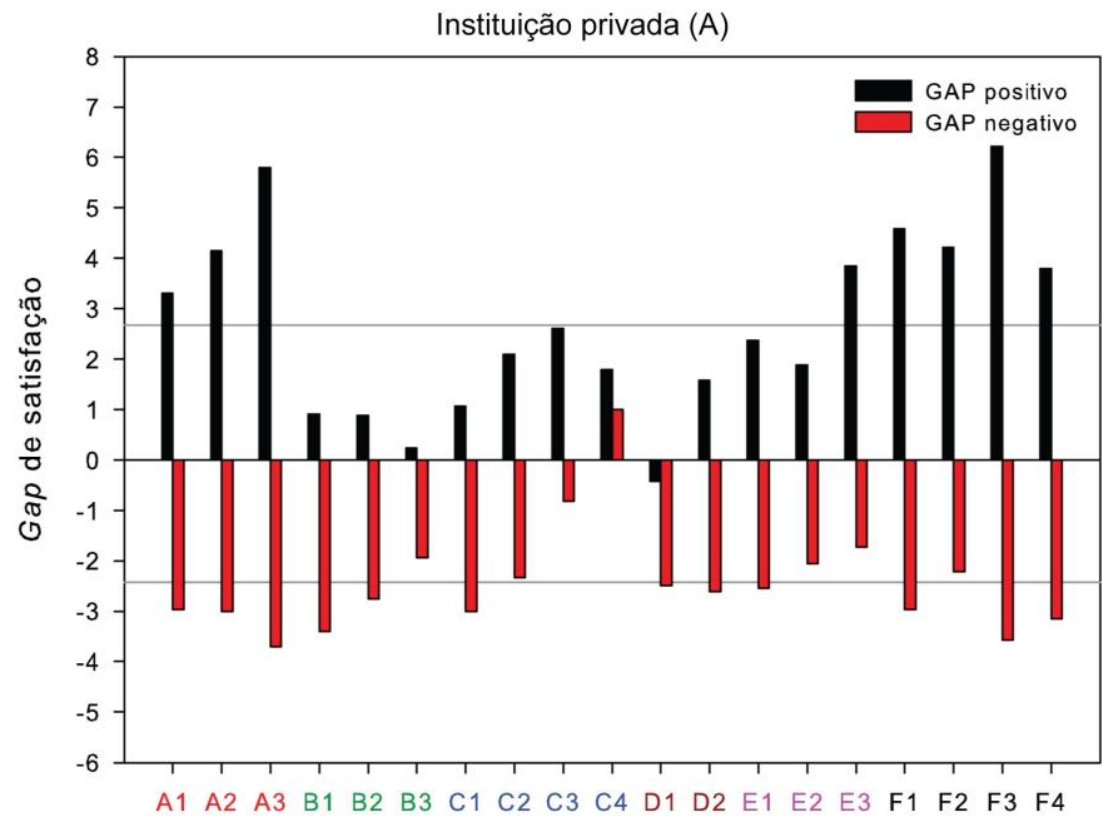

Atributos

Instituição pública (B)

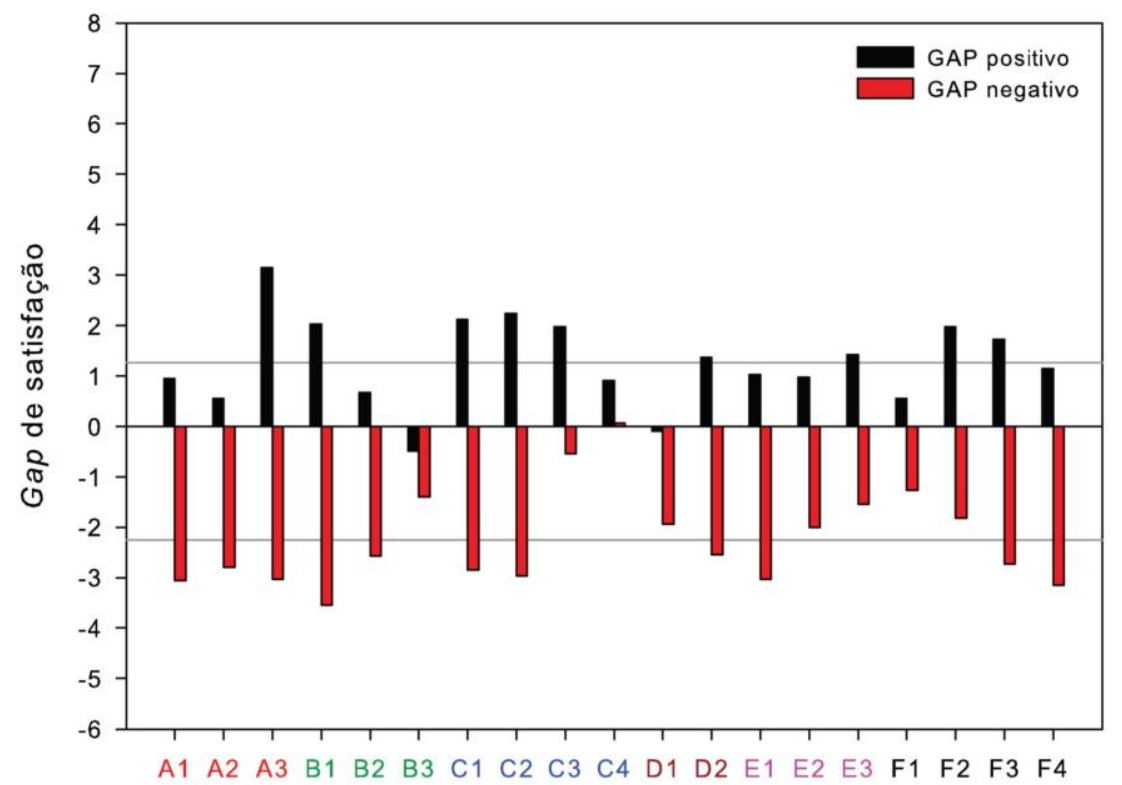

Atributos

$\begin{array}{ll}\text { A1 } & \text { Atendimento da secretaria } \\ \text { A2 } & \text { Acesso à coordenação do curso } \\ \text { A3 } & \text { Laboratório de impressão } \\ \text { B1 } & \text { Atualização dos professores } \\ \text { B2 } & \text { Titulação dos professores } \\ \text { B3 } & \text { Exigência por parte dos professores } \\ \text { C1 } & \text { Experiência prática dos professores } \\ \text { C2 } & \text { Diversidade de métodos de ensino } \\ \text { C3 } & \text { Rel. entre teoria e prática } \\ \text { C4 } & \text { Rel. ensino presencial e extraclasse }\end{array}$

D1 Relacionamento com professores

D2 Atendimento de professores extraclasse

E1 Contrib. para o desempenho profissional

E2 Oferta de atividades extracurriculares

E3 Existência de empresa júnior

F1 Vagas no estacionamento

F2 Quantidade de títulos da biblioteca

F3 Modernidade dos laboratórios de inf.

F4 Estrutura física da sala de aula

C4 Rel. ensino presencial e extraclasse

Figura 2: Análise dos atributos através dos gaps corrigidos para a instituição privada (A) e pública (B). 
$\mathrm{Na}$ instituição privada (figura 2A), os atributos nível de exigência por parte dos professores (B3), diversidade de métodos de ensino (C2), relação entre teoria e prática (C3), relação ensino presencial e extraclasse (C4), os dois atributos relacionados a atitudes (D1 e 2), contribuição para desempenho profissional (E1) e oferta de atividades extraclasse (E2) são considerados neutros, pois, ambos gap - positivo e negativo - são baixos e, por isso, podem não se tratarem de prioridades para a instituição.

A existência de empresa júnior (E3) e a quantidade de títulos na biblioteca (F2) possuem característica atrativa, por possuir apenas altos valores de gap positivo. Já a atualização (B1), titulação (B2) e experiências práticas (C1), por parte dos professores, podem ser considerados como obrigatórios. Os demais atributos da categoria atendimento (A1, 2 e 3), quantidade de vagas no estacionamento (F1), modernidade dos laboratórios de informática (F3) e a qualidade das estruturas físicas das salas de aula (F4), pelo gráfico são considerados unidimensionais.

Na instituição pública (figura 2B), os atributos nível de exigência por parte dos professores (B3), relação ensino presencial e extraclasse (C4), o relacionamento com os professores (D1), oferta de atividades extraclasse (E2) e a quantidade de vagas no estacionamento (F1) são considerados neutros.

A relação entre teoria e prática (C3), a existência de empresa júnior (E3) e quantidade de títulos na biblioteca (F2) possuem características atrativas. São considerados obrigatórios o atendimento a secretaria (A1), acesso a coordenação (A2), titulação dos professores (B2), contribuição para desempenho profissional (E1) e qualidade das estruturas físicas das salas de aula (F4). Atendimento do laboratório de impressão (A3), atualização dos professores (B1), experiência práticas (C1) e diversidade de métodos de ensino (C2), atendimento extraclasse (D2) e a modernidade dos laboratórios de informática (F3) são atributos unidimensionais.

De um modo geral entre as duas instituições, percebe-se que a privada (figura 2A), pode apresentar uma grande variação na satisfação dos seus atributos quando se altera o desempenho dos mesmos. Já na pública (figura 2B), estas mudanças na satisfação são bem menos explícitas, principalmente nas categorias atendimento aos alunos e infraestrutura das instituições.

\subsection{Análise da matriz de desempenho versus importância}

O gráfico de dispersão da figura 3A e B mostra a matriz de importância versus desempenho para os atributos nas duas instituições estudadas. Para a divisão dos quadrantes as linhas divisórias foram estabelecidas no nível de satisfeito (1) e na média, respectivamente para o eixo desempenho e importância.

Para a instituição privada (figura 3A), podemos observar uma clara separação de dois clusters. No quadrante I podemos encontrar cinco atributos, sendo eles: os três atributos da categoria capacitação dos professores (B1, B2 e B3), experiência práticas dos professores (C1) relacionamento com os professores (D1). Esses atributos podem ser considerados os pontos fortes do curso, com destaque para o relacionamento com os professores (D1), o qual mostra relativamente aos demais alta importância para os alunos desta instituição e, ao mesmo tempo, apresenta um desempenho mais que satisfeito. Já os demais atributos que são considerados fracos ou fracos menores desta instituição são exibidos nos quadrantes II e III (figura 3A). 

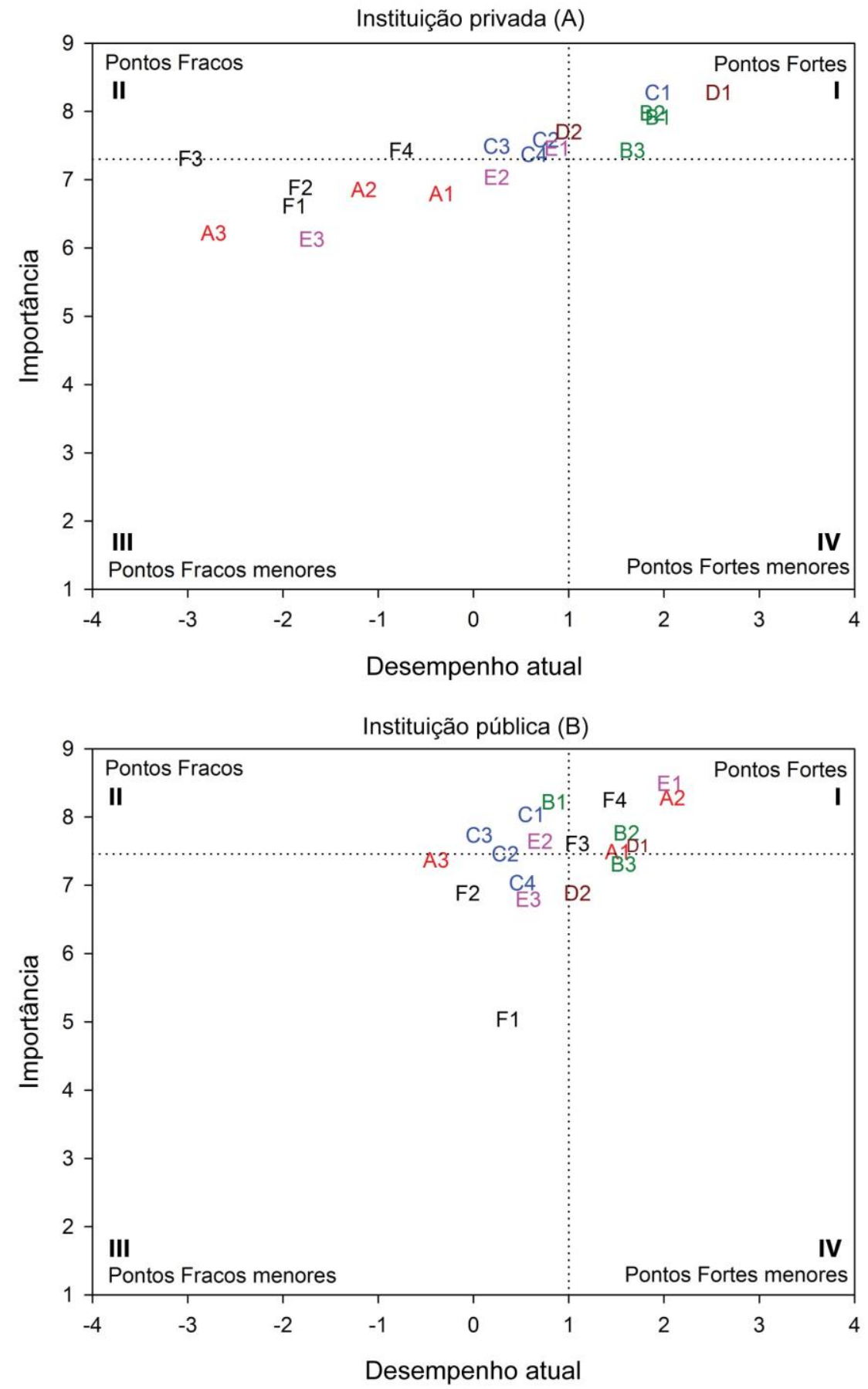
D1 Relacionamento com professores
D2 Atendimento de professores extraclasse
E1 Contrib. para o desempenho profissional
E2 Oferta de atividades extracurriculares
E3 Existência de empresa júnior
F1 Vagas no estacionamento
F2 Quantidade de títulos da biblioteca
F3 Modernidade dos laboratórios de inf.
F4 Estrutura física da sala de aula

3 Rel. entre teoria e prática

C4 Rel. ensino presencial e extraclasse

Figura 3: Análise dos atributos através do desempenho versus importância para a instituição privada (A) e pública (B). 
Como destaque, aponta-se o atendimento do laboratório de impressão (A3) e a modernidade das salas de informática (F3) como atributos que devem receber muita atenção.

Na figura 3B é mostrada a matriz para com os atributos na instituição pública. Diferentemente da divisão em clusters observada na privada, percebe-se apenas um grande cluster se concentrando no nível de satisfação (1), o que mostra que não existe uma diferença tão marcante entre as satisfações como caracterizada na instituição privada. Como pontos fortes destacamos o acesso à coordenação (A2) e a contribuição para o desempenho profissional (E1).

O laboratório de impressão (A3) merece destaque pelo relativo baixo desempenho quanto aos demais atributos e merece uma ação de estratégia para melhorar seu desempenho. Esse fato pode ser devido à compatibilidade parcial entre os horários de funcionamento do laboratório de impressão e fotocópia e o horário das aulas do curso, que são noturnas.

\subsection{Análise global e interpretação}

Para uma melhor compreensão da pesquisa, apresenta-se na tabela 1 um resumo dos resultados encontrados para cada atributo.

$\mathrm{Na}$ instituição privada, para determinar quais dos atributos devem ser melhorados, segundo a classificação de importância versus desempenho (D/I), os atributos $A(1,2$ e 3); C (2, 3 e 4); $E(1,2$ e 3$)$ e $F(1,2,3$ e 4) mostram-se como prioritários - pontos fracos - e que carecem todos melhorias para aumentar a satisfação dos alunos. Porém, ao se observar estes mesmos atributos pelo resultado do modelo Kano, verifica-se que destes C3 e C4 são atrativos, assim a meIhoria não é obrigatória, pois seu baixo desempenho não traz grande insatisfação. Já os demais são unidimensionais e, além de serem pontos fracos, trazem insatisfação e se melhorados causam muita satisfação. Neste sentido, necessitam atenção no planejamento da gestão como forma de elevar a satisfação dos usuários do serviço educacional. Destes últimos, numa análise isolada segundo seus gaps positivos e negativos, podem-se elencar os atributos laboratório de impressão (A3) e modernidade dos laboratórios de informática (F3) como urgentes para uma melhoria na satisfação.

$\mathrm{Na}$ instituição pública a classificação $\mathrm{D} / \mathrm{I}$ mostra como atributos fracos e que devem ser melhorados os itens A (3); B (1); C (1, 2, 3 e 4); E (2 e 3) e F (1 e 2). Já o modelo Kano mostra que deste, C3 e C4 são apenas atrativos e não necessariamente precisam ser melhorados. Os demais são unidimensionais e um obrigatório, fazendo com que a sua oferta ou melhoria pode ocorrer aumento na satisfação dos alunos.

Tabela 1: Classificação dos atributos quanto a sua prioridade para melhorias.

\begin{tabular}{|c|c|c|c|c|c|}
\hline Tipo & Atributo & $\begin{array}{l}\text { Classificação mode- } \\
\text { lo Kano }\end{array}$ & Classificação gaps & Clas. $\mathrm{D} / \mathrm{I}^{5}$ & $\begin{array}{c}\text { Decisão a respeito de me- } \\
\text { Ihorias }^{6}\end{array}$ \\
\hline \multirow{7}{*}{$\begin{array}{l}\frac{\pi}{0} \\
\stackrel{\pi}{\frac{\pi}{2}} \\
\frac{2}{2}\end{array}$} & A1 & Unidimensional & Unidimensional & Fraco $^{-7}$ & Prioritário \\
\hline & $\mathrm{A} 2$ & Unidimensional & Unidimensional & Fraco - & Prioritário \\
\hline & A3 & Unidimensional & Unidimensional & Fraco - & Urgente \\
\hline & B1 & Unidimensional & Obrigatório & Forte & Manter \\
\hline & B2 & Unidimensional & Obrigatório & Forte & Manter \\
\hline & B3 & Unidimensional & Neutro & Forte & Manter \\
\hline & $\mathrm{C} 1$ & Unidimensional & Obrigatório & Forte & Manter \\
\hline
\end{tabular}




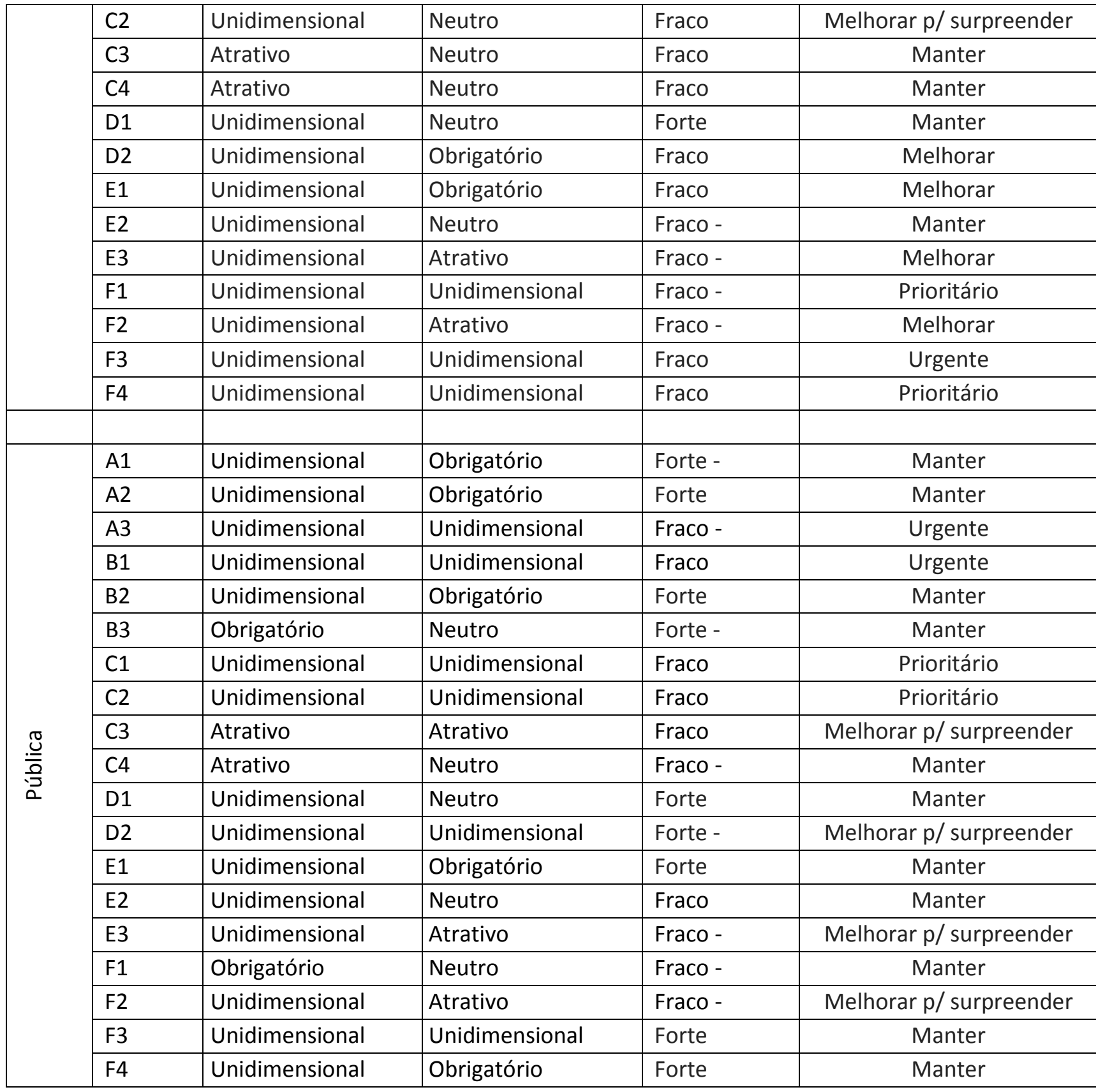

Entretanto, ao se analisar a classificação dos gaps, observa-se que apenas A3, B1, C1 e 2 tendem, consideravelmente, trazer aumento na satisfação em relação a satisfação atual. Destes podem-se sugerir a melhoria do laboratório de impressão (A3) e a atualização dos professores (B1) como necessidades de melhoria urgente, devido ao grande aumento na satisfação e diminuição na insatisfação que poderá trazer, sem desconsiderar a experiência prática dos professores (C1) e diversidade de métodos de ensino (C2) que, após, são prioritários para melhoria.

Nesta instituição também foi observado que vários atributos, apesar de fracos, são apenas atrativos ou são fortes, porém, unidimensionais e, desta forma, dependendo do gestor da instituição, podem ser melhorados e gerar surpresa na satisfação geral dos alunos. 


\section{6 Índice de satisfação global e satisfação geral}

Também foram feitos questionamentos aos alunos a respeito de recomendação, satisfação e expectativa atendida quanto à instituição. As respostas são apresentadas na figura 4.

Recomendaria a instituição Satisfeito com a instituição Atende minhas expectativas

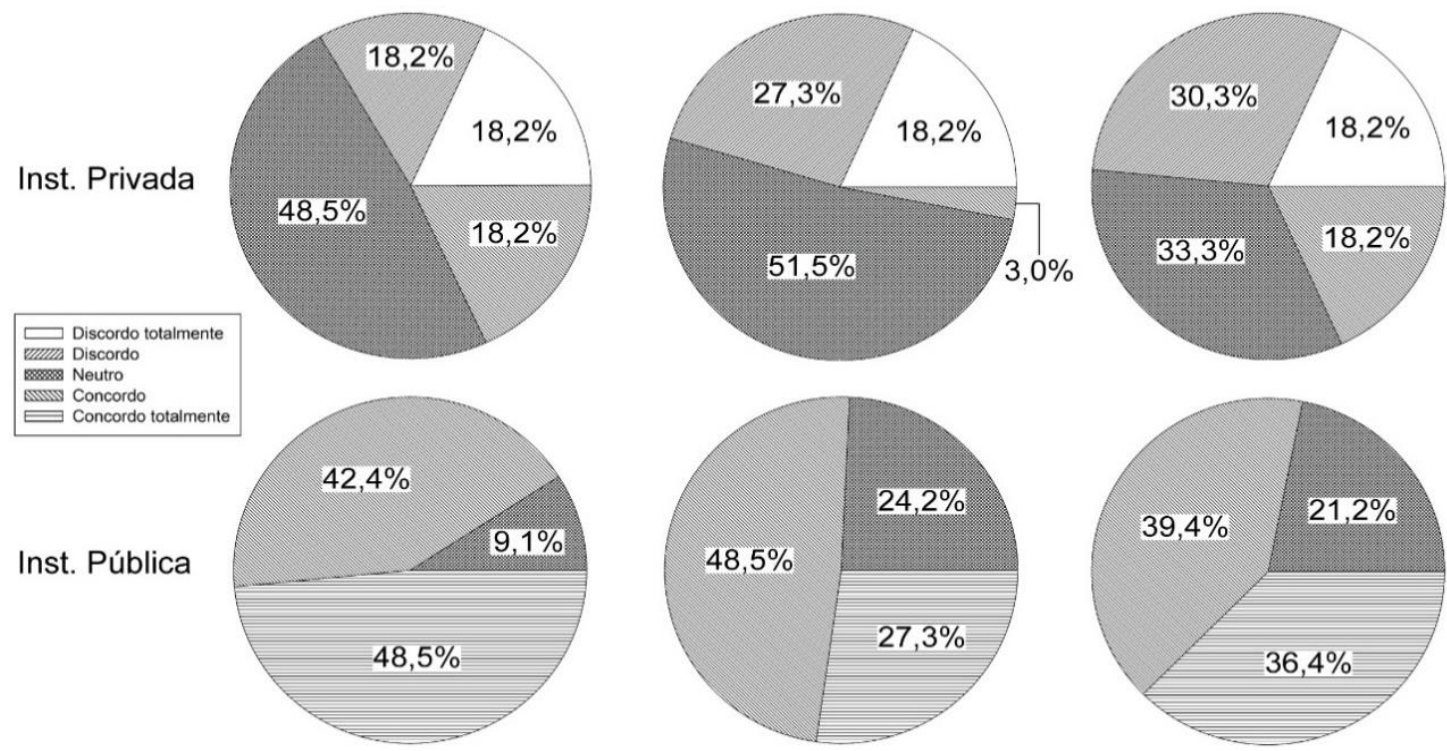

Figura 4: Respostas dos alunos da instituição privada (A) e pública (B) estudadas, quando perguntados sobre as seguintes questões: Eu recomendaria esta instituição para amigos e parentes? Estou satisfeito com a instituição? 0 curso que faço atende minhas expectativas?

No quesito recomendação da instituição privada quase a metade dos respondentes 48,5\% - é neutra, com poucos concordando - 18,2\% - nesta questão. Já na pública, 48,5\% responderam que concordam plenamente em recomendar a instituição. Já na satisfação com a organização, na instituição privada percebe-se que existe um grande descontentamento com a instituição, quando apenas 3\% dos respondentes concordam que estão satisfeitos. Enquanto na pública, $75,8 \%$ dos respondentes estão entre concordar e concordar plenamente com a afirmação. E quando se verifica quanto ao atendimento das expectativas, apenas $18,2 \%$ afirmam que concordam, os demais ou são neutros, discordam ou discordam plenamente quanto ao atendimento das suas expectativas iniciais na instituição privada. Na pública $75,8 \%$ concordam ou concordam plenamente que o curso atende suas expectativas.

A satisfação global calculada pelo ACSI, considerando para isso os 19 atributos deste estudo, mostra que a instituição privada apresenta um índice ACSI de $51,6 \%$, enquanto a pública mostra um maior índice ACSI de 62,1\%.

\section{CONSIDERAÇÕES FINAIS}

A instituição escolar é um dos elementos motrizes do ensino e da aprendizagem. A satisfação dos alunos é um fator indissociável das categorias que atribuem qualidade ao ensino: atendimento, capacitação dos professores, métodos de ensino, atitude, conteúdo e infraestrutura. Pela percepção discente, conferir significados numéricos aos atributos de análise compreende desvendar indicativos sobre as potencialidades, fragilidades, ameaças e oportunidades, com vistas a qualificar o ensino escolar técnico profissionalizante. $O$ estudo possibilitou fazer um compa- 
rativo com foco na educação profissional técnica em duas instituições - uma pública e outra privada - de Santa Maria, no Rio Grande do Sul. Com a aplicação de um questionário foi possível avaliar a satisfação dos alunos do último semestre de nível técnico em Administração e Contabilidade.

Este estudo aponta que, enquanto $75,8 \%$ estão satisfeitos com a instituição pública, apenas $3 \%$ dos alunos vinculados à privada concordam que estão satisfeitos. O ACSI, considerando os 19 atributos deste estudo, mostra que a instituição privada apresenta um índice ACSI de 51,6\%, enquanto a pública mostra um maior índice ACSI de 62,1\%. Além disso, o trabalho evidencia os atributos que, por meio da percepção dos alunos, podem ser considerados pontos fortes e fracos, em cada instituição. Ao mesmo tempo, visando uma melhoria na satisfação dos alunos, o trabalho apontou os atributos mais indicados para essa intervenção, com vistas a máxima performance nas melhorias. Nesse sentido, para a instituição privada, observa-se que existem muito mais atributos a serem levados em consideração de melhorias, em geral, em comparação à pública. Como pontos para ingerência, de modo mais urgente, estão o laboratório de impressão e a modernização dos laboratórios de informática.

$\mathrm{Na}$ instituição pública se destaca uma boa distribuição homogênea dos atributos dentro categorias principais que, atualmente, levam satisfação aos alunos. Como quesitos que precisam ser geridos de modo urgente estão alterações no quesito laboratório de impressão e na atualização dos professores responsáveis pelas disciplinas cursadas.

Ressaltamos, ainda, que nas duas instituições existem alguns atributos que, mesmo sendo considerados fracos ou fortes, não apresentam a necessidade de intervenção atualmente, pois se caracterizam por pouco interferirem na satisfação dos alunos questionados neste estudo.

A especificidade do estudo faz com que os resultados não possam ser generalizados, porém, os dados da pesquisa ampliam a base de conhecimento sobre aspectos relacionados à satisfação geral dos alunos de instituição pública e privada, bem como sobre as características que influenciam na percepção discente sobre a qualidade do curso. Como recomendação geral, futuros estudos podem ser realizados com o objetivo de compreender, por exemplo, a situação entre a gestão educacional pública e a gestão educacional privada, com vistas a identificar as similaridades e dissonâncias, comparando a percepção do aluno sobre sua influência na qualidade do ensino escolar. Ademais, outros aspectos da gestão de qualidade, como a avaliação do relacionamento por parte dos docentes, são oportunos em pesquisas futuras.

\section{REFERÊNCIAS}

1. ARAGÃO, J. E. O. S. As políticas de avaliação e a qualidade do ensino superior brasileiro na ótica dos gestores de cursos de graduação. Revista de Educação, Ciência e Cultura, v. 17, p. 51-65, 2012.

2. BERGER, C. et al. Kano's methods for understanding customer-defined quality. Center for Quality Management Journal, v. 2, n. 4, p. 33-35, 1993.

3. CARLINI, A. L; RAMOS, M. P. A avaliação do curso. In: LITTO, F. M; FORMIGA, M. Educação a distância: o estado da arte. São Paulo: Pearson Education, 2009, p. 161-165.

4. DOURADO, L. F; OLIVEIRA, J. F; SANTOS, C. A. A qualidade da educação: conceitos e definições. Brasília: Inep, 2007. 
5. FORNELL, C. et al. The American customer satisfaction index: nature, purpose, and findings. Journal of Marketing, v. 60, p.7-18, 1996.

6. GOLDBARG, Marco César. Educação e qualidade: repensando conceitos. Revista Brasileira de estudos Pedagógicos, Brasília, v. 79, n.193, p. 35-62, 1998.

7. KANO, N. Attractive quality and must-be quality. The Journal of Japanese Society for quality Control, v. 14, p. 39-48, abr. 1984.

8. KOTLER. P. Princípios de marketing. Rio de Janeiro: PHB, 1998.

9. MARCHETI, A. P. C. et al. Educação à distância: diretrizes e contribuições para a implantação dessa modalidade em instituições educacionais. Colabor@ (Curitiba) - Revista digital da CVARICESU. v. 3, n. 9, 2005.

10. MORAN, J. M; MASETTO, M; BEHRENS, M. A. Novas tecnologias e mediação pedagógica. Campinas: Papirus, 2007. Disponível em: <www.eca.usp.br/prof/moran/textosead.htm>. Acesso em 5 jun. 2013.

11. NÓVOA, A. Os professores na virada do milênio: do excesso dos discursos à pobreza das práticas. Educação e Pesquisa, São Paulo, v. 25, n. 1, p. 11-20, jan./jun. 1999.

12. SAMULSKI, D. Psicologia do esporte: teoria e aplicação prática. Belo Horizonte: UFMG, 1995.

13. SOUZA, F. J. S. F. Satisfação de clientes - o caso de uma empresa industrial. 115p. Dissertação (Mestrado em Marketing). Universidade de Coimbra, Portugal, 2011.

14. SOUZA, S. A; REINERT, J. N. Avaliação de um curso de ensino superior através da satisfação/insatisfação discente. Avaliação (Campinas). v.15, n.1, p. 159-176, 2010.

15. TONTINI, G. Determining the degree of satisfaction of customer requirements: a modified Kano method. California Journal of Operations Management, Stanislaus - California - EUA, v. 1, n. 1, p. 95-103, 2003.

16. TONTINI, G; SANT'ANA, A. J. Interação de atributos atrativos e obrigatórios de um serviço na satisfação do cliente. Produção (São Paulo. Impresso), v. 18, p. 112-125, 2008.

17. TONTINI, G; SANT'ANA, A. J. Identificação de atributos críticos de satisfação em um serviço através da análise competitiva do gap de melhoria. Gestão e Produção, São Carlos, v. 14, n. 1, p. 43-54, 2007.

18. TONTINI, G; SILVEIRA, A. Identification of critical attributes of success in products and services: an alternative to importance - performance analysis. In: 2005 BALAS Annual Conference, 2005, Madrid. Proceedings of the 2005 BALAS Annual Conference. Madrid: Instituto de Empresa, 2005. p. 1-15.

19. WALTER, S. A; TONTINI, G; DOMINGUES, M. J. C. S. Análise da satisfação do aluno para melhoria de um curso de Administração. Revista Faces, v. 6, p. 52-70, 2006.

20. XAVIER, A. C. R. A gestão da qualidade e a excelência dos serviços educacionais: custos e benefícios de sua implantação. Brasília: Ipea, 2006.

21. ZEITHAML, V. A.; BITNER, M. J. Marketing de serviços: a empresa com foco no cliente. Porto Alegre: Bookman, 2003. 